\title{
Canine tick-borne diseases in pet dogs from Romania
}

\author{
Martin O. Andersson ${ }^{1}$, Conny Tolf ${ }^{1}$, Paula Tamba ${ }^{2}$, Mircea Stefanache ${ }^{3}$, Jonas Waldenström ${ }^{1}$, Gerhard Dobler $^{4^{*}}$ \\ and Lidia Chițimia-Dobler ${ }^{2,4}$
}

\begin{abstract}
Background: Tick-borne diseases are of substantial concern worldwide for animals as well as humans. Dogs have been a human companion for millennia, and their significant impact on human life renders disease in dogs to be of great concern. Tick-borne diseases in dogs represent a substantial diagnostic challenge for veterinarians in that clinical signs are often diffuse and overlapping. In addition, co-infections with two or more pathogens enhance this problem further. Molecular methods are useful to disentangle co-infections and to accurately describe prevalence and geographical distribution of tick-borne diseases. At this point, this information is lacking in many areas worldwide. Romania is one such area, where prevalence and distribution of several important pathogens need to be further investigated. To address this, we screened blood samples from 96 sick dogs with molecular methods for eight different pathogens including Babesia spp., Theileria spp., Hepatozoon spp., Anaplasma spp., Ehrlichia spp., "Candidatus Neoehrlichia mikurensis", Mycoplasma spp., and Borrelia spp.

Results: As many as $45 \%$ (43/96) of the dogs in the study were infected with protozoan parasites. Babesia canis was the most frequent of these (28 infected dogs), whereas Hepatozoon canis was detected in 15\% (14/96) and Babesia gibsoni was found in a single sample. Bacterial infection with Mycoplasma spp. occurred in 18\% (17/96) of the sampled dogs. Obtained bacterial sequences revealed the occurrence of two species: Mycoplasma canis and "Candidatus Mycoplasma haematoparvum". In several cases co-infection with protozoan parasites and Mycoplasma sp. were detected. All dogs were negative for Anaplasma spp., Ehrlichia spp., "Ca. Neoehrlichia mikurensis", and for Borrelia spp.

Conclusions: The results from the present study reinforce the notion that Babesia canis is an important pathogen in the Romanian dog population. However, more surprisingly, another protozoan species, H. canis, seems to be infecting dogs to a larger extent than previously recognized in Romania. Well-known tick-borne bacterial disease agents such as Anaplasma spp. and Borrelia spp. were not detected. In contrast, less wellstudied bacteria such as hemotropic Mycoplasma spp. were detected frequently. Moreover, co-infection might aggravate disease and complicate diagnosis and should be further studied in dogs.
\end{abstract}

Keywords: Dogs, Canis familiaris, Vector-borne diseases, Tick-borne diseases, Romania

\section{Background}

Dogs are most likely the oldest domestic animal and have for many millennia been a human companion. Diseases in dogs are of great concern, both directly because of costs for owners and suffering in dogs, and indirectly because of the risk for transmission of pathological agents from dogs to humans. Canine vector-borne

\footnotetext{
* Correspondence: gerharddobler@msn.com

${ }^{4}$ Bundeswehr Institute of Microbiology, German Center of Infection Research

(DZIF) Partner, Neuherbergstrasse 11, D-80937 Munich, Germany

Full list of author information is available at the end of the article
}

diseases (CVBDs) are caused by a wide variety of different bacteria, viruses and eukaryotic parasites that are spread by arthropod blood-sucking vectors, mainly ticks and mosquitoes [1]. Globally, the increasing spread of arthropod vectors and associated CVBDs can be explained by several key components, such as ecological and climatic factors and increased mobility of human and animal populations. Combined, these factors have caused a global increase in the distribution of CVBDs $[1,2]$. In many areas ticks are the most important arthropod vectors, transmitting a wider variety of CVBDs than any 
other group of vectors [3, 4]. Several of these pathogens are of substantial zoonotic concern [1]. The probability of dog to human transmission will possibly rise with an increasing number of pet dogs as well as an expanding geographical distribution of several significant vector species.

CVBDs represent a substantial diagnostic challenge for veterinarians, because clinical signs induced by different vector-borne pathogens might be diffuse and overlapping or because diagnostic characteristics are obscured due to co-infections with two or more of these agents [1]. Diagnostic confirmation of CVBDs should include historical exposure to arthropod vectors, compatible clinical signs and physical examination findings, as well as laboratory confirmation with cytological, serological and molecular test results [5]. During the past decade, molecular techniques (e.g. PCR-based methods) have proven to be useful for diagnostic confirmation of many CVBDs, whereas serology and cytology have been used historically in epidemiological surveys or for diagnostic purposes [5].

Romania has a high biodiversity and 25 ixodid tickspecies are present, resulting in the presence of many tick-borne pathogens. Despite this, there is only limited information regarding the prevalence of canine tick-borne infections in dogs. Previous studies have concluded that the seroprevalence to a number of well-known tick-borne pathogens were relatively low, with the exception of $B$. canis to which dogs commonly showed an immune response [6]. In addition, studies using molecular techniques have confirmed infection with Babesia spp. in dogs [7-9]. Infection with the protozoan parasite Hepatozoon canis is known from a single case [10], as well as in four Romanian dogs imported to Germany [11]. Hepatozoon canis is one of the most widespread canine tick-borne infections, infecting dogs in large parts of the world [12]. In North-America an additional species of this parasite, $H$. americanum, also causes disease in dogs [13].

The bacterial family Anaplasmataceae contains several species that infect various animal species [14]. In Europe, the main causative agent is Anaplasma phagocytophilum [15]. In Romania, this species is occurring in ticks [16], while the reported seroprevalence against this bacterium in the Romanian dog population is 5.5\% [6]. Moreover, similar results have been reported from other eastEuropean countries [17, 18]. Other species belonging to Anaplasmataceae have also been found in Romanian dogs, such as A. platys [10], and E. canis, to which $2.1 \%$ of dogs were seropositive [6]."Candidatus Neoehrlichia mikurensis" is another member of the Anaplasmataceae. This tick-borne bacterium [19-21] has been detected in several mammal species, including humans [22-25]. Previous studies concerning this bacterium have shown that it has the ability to infect dogs [26] and that it is present in ticks in Romania [16, 27]. However, the scale to what this pathogen is infecting dogs has rarely been investigated. Infections with other bacterial pathogens such as Borrelia spp. seem, based on serological analyses, to be relatively rare $(0.5 \%)$ in the dog population in Romania [6]. Correspondingly, Mycoplasma spp. has only been detected once in a dog in Romania using PCR [7]. The aim of this testing was the screening of pet dogs in the area of Snagov, Southern Romania for the occurrence of selected tickborne protozoan and bacterial infections. A combination of conventional PCR and real-time PCR assays targeting Babesia spp., Theileria spp., Hepatozoon spp., Anaplasma spp., Ehrlichia spp., "Ca. Neoehrlichia mikurensis", Mycoplasma spp., and Borrelia spp. in blood samples was used.

\section{Methods}

Blood samples were collected during 2013 and 2014, in Snagov (Iflov County) located in the southern part of Romania by local veterinarians. The tested samples were taken for routine diagnosis from dogs brought to the local veterinary cabinet for diagnosis and treatment of symptoms supposed to be caused by tickborne infection. The samples were not collected for study reasons. Therefore no epidemiological data were available, except that all dogs had a tick infestation history and were residential and never left the surroundings of Snagov, Ilfov County. The material used in this study consisted of surplus material from clinical investigations. No formal ethical approval was gained. The owners were asked if they agree if the surplus material can be used for additional diagnostic testing. Criteria for the inclusion of samples were epidemiological aspects (exposure to ticks, such as previous infestation and/or residence or visits to tickinfested areas), clinical manifestation (including but not limited to anorexia, depression, fever, jaundice, lethargy/apathy, paleness of external mucosal membranes, weakness), and with or without findings of biochemical abnormalities in hemoglobin, GOT (glutamic-oxaloacetic transaminase), GOP (glutamic-phosphate transaminase), urea and creatinine (all clinical chemistry parameters tested by Reflovet, Roche, Mannheim, Germany). As the sampling of blood from sick dogs was not done as an epidemiological study, different veterinarians provided the samples only with rudimental data from particular dogs, which unfortunately did not allow epidemiological analysis of data in correlation with the results of the PCR testing. DNA was extracted from EDTA-blood using the MagNa Pure LC Instrument and the MagNa Pure LC DNA Isolation Kit I (Roche Applied Science, Mannheim, Germany), using $200 \mu \mathrm{l}$ of EDTA blood and DNA elution in a final volume of $100 \mu \mathrm{l}$. 


\section{Conventional PCR}

Conventional PCR amplification of Babesia/Theileria/ Hepatozoon was performed with the forward primer 5'GYY TTG TAA TTG GAA TGA TRG-3' and reverse primer 5'-TAG TTT ATR GTT ARG ACT ACG-3' that amplify a 411-499 nt fragment of the 18S rRNA gene of Babesia spp., Theileria spp. and Hepatozoon spp. These primers were modified from primers originally designed to amplify only Babesia spp. [28].

PCR targeting the 16S rRNA gene of Anaplasmataceae was performed with the primers ehr521 and ehr747 according to Pancholi et al. [29], amplifying a 202 bp fragment of the 16S rRNA gene. These primers have been shown to amplify various Anaplasmataceae species, including A. phagocytophilum and Ehrlichia chaffeensis; they also amplify Rickettsia rickettsii and Bartonella henselae [30]. Mycoplasma spp. were amplified with the primers HBT-F and HBT-R [31] that amplify a 595-618 nt fragment of the 16S rRNA gene in various Mycoplasma spp. PCR conditions for all assays were as follows; $94{ }^{\circ} \mathrm{C}$ for 5 min followed by 35 cycles consisting of $94{ }^{\circ} \mathrm{C}$ for $30 \mathrm{~s}$, $55{ }^{\circ} \mathrm{C}$ for $30 \mathrm{~s}$ and $72{ }^{\circ} \mathrm{C}$ for $30 \mathrm{~s}$, followed by $72{ }^{\circ} \mathrm{C}$ for 10 minutes. PCR reactions were performed in a total reaction volume of $25 \mu \mathrm{l}$, which included approximately 20 40 ng of total genomic DNA and by using the Platinum ${ }^{\circ}$ Taq DNA Polymerase (Invitrogen ${ }^{\text {Twx }}$, Karlsruhe, Germany). All positive PCR amplicons were precipitated and sequenced using the BigDye V 1.1 Cycle Sequencing Kit (Applied Biosystems) and an ABI 3100 sequencer. The sequences were manually edited in the program Geneious 8.1.9 and aligned with relevant sequences published in the GenBank database.

\section{Real-time PCR}

The occurrence of "Ca. N. mikurensis" was investigated with a real-time PCR assay targeting the groEL-gene [21]. Borrelia spp. was amplified with a real-time PCR assay targeting the $16 \mathrm{~S}$ rRNA gene as previously described [32]. The occurrence of $A$. phagocytophilum was further investigated with a real-time assay with primers from Courtney et al. [33] targeting the $m s p 2$ gene. All real-time PCR reactions were performed in a Light Cycler 480 (Roche, Switzerland) instrument, using the $\mathrm{iQ}^{\mathrm{m}}$ SYBR $^{\circ}$ Green Supermix (Bio-Rad Laboratories, USA). Thermal cycling conditions included an initial denaturation step at $95{ }^{\circ} \mathrm{C}$ for $3 \mathrm{~min}$, followed by 45 cycles of $95{ }^{\circ} \mathrm{C}$ for $15 \mathrm{~s}, 60{ }^{\circ} \mathrm{C}$ for $30 \mathrm{~s}$ and $72{ }^{\circ} \mathrm{C}$ for $30 \mathrm{~s}$ for all assays.

\section{Results}

Blood samples from 96 dogs were included in the study. The most prevalent pathogen was Babesia spp., infecting $30 \%(29 / 96)$ of the investigated dogs. The dominating species amongst these was $B$. canis ( 28 of 29 cases). Two different $B$. canis genotypes were detected, differing at two nucleotide positions. Twenty-five out of 28 parasite sequences (KY433316) were identical to a $B$. canis sequence found in dogs in Poland and Estonia (KT844900 and KT008057, respectively), whereas the three remaining sequences from Romanian dogs (KY433317) were identical to sequences found in Romanian ticks (KY433323), and also found in dogs from Poland (KT844897). A single nucleotide sequence of B. gibsoni (KY433318) was obtained (i.e. corresponding to a prevalence of $1 \%$ ). This was identical to a sequence from Slovakia, GenBank accession number KP737862 [34]. Previously published sequences from B. gibsoni in Romania [9] partially covered a different fragment of the 18S rRNA gene than that reported in the present study. However, all previously published sequences differed on at least one nucleotide position in the $280 \mathrm{bp}$ fragment that overlapped between sequences. Fifteen percent of the dogs (14/96) were infected with $H$. canis. Three different $H$. canis genotypes were found. The most common of these (KY433319), with 10 obtained sequences, were identical to a genotype previously identified in ticks in Romania (KY433326). Another genotype (KY433320), with three additional sequences, was obtained, which differed from the previous genotype, mentioned above, at a single nucleotide position. This genotype was also identical to a sequence previously found in Romanian ticks (KY433327). A third genotype (KY433321) occurred in a single case, and this was identical to a genotype obtained from a fox in Austria (KM115984).

Bacterial infections in the samples were also detected. Mycoplasma spp. occurred in 18\% of the dogs (17/96) and sequencing revealed two species; Mycoplasma haemocanis in 9\% (9/96) and "Candidatus Mycoplasma haematoparvum" in 8\% (8/96), respectively. Mycoplasma haemocanis in the present study (KY433883) was identical to a sequence found in a Portuguese dog (GQ129118). The obtained "Ca. M. haematoparvum" sequence (KY433884) was identical to a sequence from a dog in Switzerland (EF416569) and also to a sequence obtained from human blood (KF366443). All dogs were negative for Anaplasma spp., Ehrlichia spp., "Ca. Neoehrlichia mikurensis", and for Borrelia spp.

Nine cases of co-infections in individual dogs were detected. The most common was concurrent infection with $H$. canis and $M$. haemocanis (3 cases) and $H$. canis and "Ca, M. haematoparvum" (3 cases). Co-infection with $B$. canis and $M$. haemocanis occurred in a single case, as did co-infection with $B$. canis and " $C a$. M. haematoparvum". Finally, the single dog with B. gibsoni infection also harbored M. haemocanis.

\section{Discussion}

Results generated in present study showed that as many as $45 \%$ (43/96) of dogs suspected to suffer from tick- 
transmitted infection were infected with apicomplexan parasites, demonstrating the potential impact of these parasites on animal health. More specifically, the study shows that almost one third of sampled dogs were infected with $B$. canis, a result broadly corresponding to previous findings based on serological screenings of Romanian dogs $[11,35]$. Furthermore, studies based on molecular screening methods have reported parasite prevalence values up to $71.4 \%$ in symptomatic Romanian dogs $[9,11]$.

Babesia gibsoni is generally less common in dogs than B. canis; however, a previous study surveying this species in Romania showed that $28.6 \%$ of symptomatic dogs were infected [9]. In the present study, only one dog was found to be infected with $B$. gibsoni. This difference is possibly due to the geographical distribution of the parasite in the country, as the previous study was based on samples taken from dogs in the western and northwestern parts of the country while dogs in the present study were located in the south. Interestingly, this species seems to colonize new geographical areas where it has not been found before, possibly due to spatial spread of vectors, or alternatively, because of spread in certain susceptible dog breeds [34]. The protozoan parasite $H$. canis has previously been reported in four dogs originating from Romania but imported to Germany [11], as well as in a dog in Romania [10]. In nearby Hungary, prevalence rates exceeding 30\% have been reported in shepherd dogs [36], and in Croatia 12\% of sampled dogs were infected by $H$. canis [37]. This parasite seems to be more common in dogs in several European countries than previously recognized. Apart from in dogs, H. canis is frequently detected in foxes, both in Romania [38] and in several other European countries [39-42].

Mycoplasma sp. have been detected in a single dog living in Romania by Hamel and colleagues [11], who screened 29 local pet dogs. Additionally, the same study detected Mycoplasma sp. in 16 out of 109 dogs living in Germany but originating from Romania, as well as in one out of 78 dogs originating from Hungary [11]. Although the geographical origin of infection remains unclear, this study concluded that almost ten percent of sampled dogs carried the parasite. The findings by Hamel and colleagues were designated as Mycoplasma haemocanis based on the size of the amplified fragment, but the sequences of these fragments were however not determined. In the present study, we report two Mycoplasma species confirmed by sequencing: $M$. haemocanis and "Ca. Mycoplasma haemoparvum". Both occurred in relatively high numbers, infecting almost one fifth of the dogs in the study, making Mycoplasma spp. the second most common pathogen. Travel history of the dogs in the present study was not reported, making it impossible to establish the actual origin of infection. However, the relatively high prevalence of both Mycoplasma species does suggest that these are well-established in Romania. Previous publications on Mycoplasma spp. in dogs reveal a wide variety of prevalences ranging from $15.4 \%$ in France, $9.5 \%$ in Italy, $2.5 \%$ in Spain and up to $40 \%$ in its neighboring country, Portugal $[43,44]$. Also, the variation in the prevalence rates between the two species of Mycoplasma seems to be extensive based on previous publications. In France, " $\mathrm{Ca}$. Mycoplasma haemoparvum", or a closely related organism, dominated and were found in $15.4 \%$ of the investigated dogs, whereas M. haemocanis only occurred in 3.3\% [43]. In contrast, in Portugal all infections were caused by $M$. haemocanis [44], whereas in Italy a relatively even distribution between the two species occurred [44]. These variations in the prevalence, especially the large variations between neighboring countries such as Spain and Portugal, show the need for large-scale screening efforts in order to better understand the spatial spread of this pathogen throughout Europe, including eastern European countries such as Romania.

None of the other bacteria tested for in this study, i.e. Anaplasma spp., Ehrlichia spp., "Ca. Neoehrlichia mikurensis", or Borrelia spp. were detected in samples from the Romanian dogs. Varying levels of seroprevalence rates to these bacteria have previously been reported; Mircean et al. [6] tested 1,146 serum samples from different regions in Romania using ELISA and found that only 129 dogs (11.3\%) were positive for any CVBDs with specific seroprevalence values as follows: for A. phagocytophilum 5.5\%, E. canis $2.1 \%$, and B. burgdorferi $0.5 \%$. Co-infection with $E$. canis and A. phagocytophilum were detected in 2 dogs $(0.2 \%)$. Immunological methods have an advantage in their ability to reveal the infection history of a particular pathogen, which enables detection of multiple previous infection episodes. This advantage may in part explain the difference in obtained prevalence values between the present study and those based on results obtained with ELISA.

Co-infection with protozoan parasites and Mycoplasma spp. were detected in $9 \%$ of the dogs in this study. Infection with more than one pathogen in dogs may possible exacerbate clinical manifestations in the infected animal, making the incubation period, clinical outcome and prognosis more unpredictable for the individual dogs [5]. Synergistic or antagonistic effects between co-infecting pathogens in dogs might either enhance or restrict the possibility of a secondary infection with another pathogen, however, such effects need to be studied either by extensive screening of dogs or by performing infection experiments in a controlled environment.

\section{Conclusions}

In the present study, protozoan parasites were commonly detected tick-borne disease agents, with B. canis 
being the most commonly detected species, reinforcing the notion that this is an important parasite in Romanian dogs. The protozoan parasite $H$. canis seems to be infecting dogs in Romania, and possibly in other European countries, to a larger extent than previously recognized and should therefore be considered as an important parasitic agent. The occurrence of this parasite in dog populations in Europe requires further studies. Well known tick-borne bacterial disease agents such as Anaplasma spp. and Borrelia spp. could not be detected in this study. In contrast, bacterial infection with Mycoplasma spp. occurred in a substantial number of the investigated dogs, indicating a rather high prevalence in the dog population in Romania. Health effects of this pathogen need further attention. Moreover, co-infections with protozoan parasites and Mycoplasma bacteria could be detected in several dogs. Co-infection might aggravate disease and complicate diagnosis and should be further studied in dogs.

\section{Abbreviation}

CVBD: Canine vector-borne disease

\section{Acknowledgements}

We are sincerely grateful to all participating dog-owners that made this study possible. This publication has been sponsored by Bayer Animal Health in the framework of the 12th CVBD World Forum Symposium.

\section{Funding}

MOA was supported by a grant from the Lawski foundation (Sven och Lilly Lawskis fond för naturvetenskaplig forskning). Laboratory work was funded by Bayer Animal Health. The funding sources had no role in the study design; in the collection, analysis and interpretation of data; or in the writing of the report.

\section{Availability of data and materials}

Not applicable.

\section{Authors' contributions}

LCD planned and organized the study. PT and MS collected samples. PT and $L C D$ extracted DNA. MOA performed PCR, sequencing and analyzed sequence data. MOA and LCD drafted the manuscript, and wrote the final version together with $C T$, JW and GD. All authors read and approved the final version of the manuscript.

\section{Competing interests}

The authors declare that they have no competing interests.

\section{Consent for publication}

Not applicable.

Ethics approval and consent to participate Not applicable.

\section{Publisher's Note}

Springer Nature remains neutral with regard to jurisdictional claims in published maps and institutional affiliations.

\section{Author details}

${ }^{1}$ Center for Ecology and Evolution in Microbial Model Systems (EEMiS), Linnaeus University, SE-391 82 Kalmar, Sweden. Institute for Diagnosis and Animal Health, Bucharest, Romania. ${ }^{3}$ PAUMI-VET Private Veterinary Clinics, Snagov, Ilfov County, Romania. ${ }^{4}$ Bundeswehr Institute of Microbiology, German Center of Infection Research (DZIF) Partner, Neuherbergstrasse 11, D-80937 Munich, Germany.
Received: 18 January 2017 Accepted: 17 March 2017

Published online: 23 March 2017

\section{References}

1. Otranto D, Dantas-Torres F, Breitschwerdt EB. Managing canine vector-borne diseases of zoonotic concern: part one. Trends Parasitol. 2009;25:157-63.

2. Otranto D, Capelli G, Genchi C. Changing distribution of canine vector-borne diseases in Italy: leishmaniosis vs. dirofilariosis. Parasit Vectors. 2009;2 Suppl 1:S2.

3. Jongejan F, Uilenberg G. The global importance of ticks. Parasitology. 2005;129:S3.

4. Estrada-Peña A, Jongejan F. Ticks feeding on humans: a review of records on human-biting Ixodoidea with special reference to pathogen transmission. Exp Appl Acarol. 1999:23:685-715.

5. Otranto D, Dantas-Torres F, Breitschwerdt EB. Managing canine vector-borne diseases of zoonotic concern: part two. Trends Parasitol. 2009;25:228-35.

6. Mircean V, Dumitrache MO, Györke A, Pantchev N, Jodies R, Mihalca AD, et al. Seroprevalence and geographic distribution of Dirofilaria immitis and tick-borne infections (Anaplasma phagocytophilum, Borrelia burgdorferi sensu lato, and Ehrlichia canis) in dogs from Romania. Vector-Borne Zoonotic Dis. 2012:12:595-604.

7. Hamel D, Röhrig E, Pfister K. Canine vector-borne disease in travelled dogs in Germany - A retrospective evaluation of laboratory data from the years 2004-2008. Vet Parasitol. 2011;181:31-6

8. Ionita M, Mitrea IL, Pfister K, Hamel D, Buzatu CM, Silaghi C. Canine babesiosis in Romania due to Babesia canis and Babesia vogeli: a molecular approach. Parasitol Res. 2012:110:1659-64.

9. Imre $M$, Farkas $R$, llie $M S$, Imre $K$, Dărăbuş $G$. Survey of babesiosis in symptomatic dogs from Romania: Occurrence of Babesia gibsoni associated with breed. Ticks Tick Borne Dis. 2013;4:500-2

10. Andersson M, Turcitu M, Stefanache M, Tamba P, Barbuceanu F, Chitimia L. First evidence of Anaplasma platys and Hepatozoon canis co-infection in a dog from Romania - a case report. Ticks Tick Borne Dis. 2013;4:317-9.

11. Hamel D, Silaghi C, Lescai D, Pfister K. Epidemiological aspects on vectorborne infections in stray and pet dogs from Romania and Hungary with focus on Babesia spp. Parasitol Res. 2012;110:1537-45.

12. Baneth G. Perspectives on canine and feline hepatozoonosis. Vet Parasitol. 2011;181:3-11.

13. Vincent-Johnson NA, Macintire D, Lindsay D, Lenz S, Baneth G, Shkap V, et al. A new Hepatozoon species from dogs: Description of the causative agent of canine hepatozoonosis in North America. J Parasitol. 1997;83:1 165-72.

14. Dumler JS, Barbet AF, Bekker CPJ, Dasch GA, Palmer GH, Ray SC, et al. Reorganization of genera in the families Rickettsiaceae and Anaplasmataceae in the order Rickettsiales: unification of some species of Ehrlichia with Anaplasma, Cowdria with Ehrlichia and Ehrlichia with Neorickettsia, descriptions of six new species combinations and designation Ehrlichia equi and 'HGE agent' as subjective synonyms of Ehrlichia phagocytophila. Int J Syst Evol Microbiol. 2001:51:2145-65.

15. Nováková M, Víchová B. Granulocytic anaplasmosis - emerging tick-borne disease of humans and animals. Biologia (Bratislava). 2010;65:925-31.

16. Kalmár Z, Sprong H, Mihalca AD, Gherman CM, Dumitrache MO, Coipan EC, et al. Borrelia miyamotoi and Candidatus Neoehrlichia mikurensis in Ixodes ricinus ticks, Romania. Emerg Infect Dis. 2016;22:550-1.

17. Víchová B, Miterpakova M, Iglódyová A. Molecular detection of co-infections with Anaplasma phagocytophilum and/or Babesia canis canis in Dirofilariapositive dogs from Slovakia. Vet Parasitol. 2014;203:167-72.

18. Farkas R, Gyurkovszky M, Lukacs Z, Aladics B, Solymosi N. Seroprevalence of some vector-borne infections of dogs in Hungary. Vector-Borne Zoonotic Dis. 2014;14:256-60

19. Sandelin LL, Tolf C, Larsson S, Wilhelmsson P, Salaneck E. Candidatus Neoehrlichia mikurensis in ticks from migrating birds in Sweden. PLoS One. 2015:10:1-11.

20. Richter D, Matuschka F-R. "Candidatus Neoehrlichia mikurensis", Anaplasma phagocytophilum and Lyme disease spirochetes in questing European vector ticks and in feeding ticks removed from people. J Clin Microbiol. 2012;50:943-7.

21. Andersson M, Bartkova S, Lindestad O, Råberg L. Co-infection with "Candidatus Neoehrlichia mikurensis" and Borrelia afzelii in Ixodes ricinus ticks in Southern Sweden. Vector-Borne Zoonotic Dis. 2013;13:438-42.

22. Andersson M, Råberg L. Wild rodents and novel human pathogen Candidatus Neoehrlichia mikurensis. Southern Sweden Emerg Infect Dis. 2011;17:12-4.

23. Welinder-Olsson C, Kjellin E, Vaht $K$, Jacobsson S, Wennerås C. First case of human "Candidatus Neoehrlichia mikurensis" infection in a febrile patient with chronic lymphocytic leukemia. J Clin Microbiol. 2010;48:1956-9. 
24. Pekova S, Vydra J, Kabickova H, Frankova S, Haugvicova R, Mazal O, et al. Candidatus Neoehrlichia mikurensis infection identified in two hematooncologic patients: benefit of molecular techniques for rare pathogen detection. Diagn Microbiol Infect Dis. 2011;69:266-70.

25. von Loewenich FD, Geissdörfer W, Disqué C, Matten J, Schett G, Sakka SG, et al. Detection of "Candidatus Neoehrlichia mikurensis" in two patients with severe febrile illnesses: evidence for a European sequence variant. J Clin Microbiol. 2010;48:2630-5.

26. Diniz PPVP, Schulz BS, Hartmann K, Breitschwerdt EB. "Candidatus Neoehrlichia mikurensis" infection in a dog from Germany. J Clin Microbiol. 2011;49:2059-62.

27. Andersson M, Zaghdoudi-Allan N, Tamba P, Stefanache M, Chitimia L. Coinfection with "Candidatus Neoehrlichia mikurensis" and Borrelia afzelii in an Ixodes ricinus tick that has bitten a human in Romania. Ticks Tick Borne Dis. 2014:5:706-8.

28. Casati S, Sager H, Gern L, Piffaretti J. Presence of potentially pathogenic Babesia sp. for human in Ixodes ricinus in Switzerland. Ann Agric Environ Med. 2006;13:65-70.

29. Pancholi P, Kolbert CP, Mitchell PD, Reed KD, Dumler JS, Bakken JS, et al. Ixodes dammini as a potential vector of human granulocytic ehrlichiosis. J Infect Dis. 1995;172:1007-12.

30. Massung RF, Slater KG. Comparison of PCR assays for detection of the agent of human granulocytic ehrlichiosis, Anaplasma phagocytophilum. J Clin Microbiol. 2003;41:717-22.

31. Criado A, Martinez-Marcos A, Buling-Sarana A, Barba-Carretero JC. Presence of Mycoplasma haemofelis, Mycoplasma haemominutum and piroplasmids in cats from southern Europe: a molecular study. Vet Microbiol. 2003:93:307-17.

32. Ornstein K, Barbour AG. A reverse transcriptase-polymerase chain reaction assay of Borrelia burgdorferi 16S rRNA for highly sensitive quantification of pathogen load in a vector. Vector-Borne Zoonotic Dis. 2006;6:103-13.

33. Courtney JW, Kostelnik LM, Zeidner NS, Massung RF. Multiplex real-time PCR for detection of Anaplasma phagocytophilum and Borrelia burgdorferi. J Clin Microbiol. 2004;42:3164-8.

34. Víchová B, Horská M, Blanarová L, Andersson M, Petko B. First molecular identification of Babesia gibsoni in dogs from Slovakia, Central Europe. Ticks Tick Borne Dis. 2016;7:54-9.

35. Imre M, Farkas R, Illie M, Imre K, Hotea I, Morariu S, et al. Seroprevalence of Babesia canis infection in clinically healthy dogs from Western Romania. J Parasitol. 2013;99:161-3

36. Hornok S, Tánczos B, de Mera IG F, de la Fuente J, Hofmann-Lehmann R, Farkas R. High prevalence of Hepatozoon-infection among shepherd dogs in a region considered to be free of Rhipicephalus sanguineus. Vet Parasitol. 2013:196:189-93.

37. Vojta L, Mrljak V, Curkovic S, Zivicnjak T, Marinculica A, Beck R. Molecular epizootiology of canine hepatozoonosis in Croatia. Int J Parasitol. 2009:39: 1129-36.

38. Ilie MS, Imre M, Imre K, Hotea I, Morariu S, Sorescu D, et al. Occurrence of Hepatozoon spp. in red foxes (Vulpes vulpes) in Romania. Parasit Vectors. 2014; 7(Suppl 1):033.

39. Mitková B, Hrazdilová K, Steinbauer V, D’Amico G, Mihalca AD, Modry D. Autochthonous Hepatozoon infection in hunting dogs and foxes from the Czech Republic. Parasitol Res. 2016;115:4167-71.

40. Farkas R, Solymosi N, Takács N, Hornyák Á, Hornok S, Nachum-Biala Y, et al. First molecular evidence of Hepatozoon canis infection in red foxes and golden jackals from Hungary. Parasit Vectors. 2014;7:303.

41. Gabrielli S, Kumlien S, Calderini P, Brozzi A, lori A, Cancrini G. The first report of Hepatozoon canis identified in Vulpes vulpes and ticks from Italy. VectorBorne Zoonotic Dis. 2010;10:855-9.

42. Duscher GG, Fuehrer H-P, Kübber-Heiss A. Fox on the run - molecular surveillance of fox blood and tissue for the occurrence of tick-borne pathogens in Austria. Parasit Vectors. 2014;7:521.

43. Kenny MJ, Shaw SE, Beugnet F, Tasker S. Demonstration of two distinct hemotropic mycoplasmas in French dogs. J Clin Microbiol. 2004;42:5397-9.

44. Novacco M, Meli ML, Gentilini F, Marsilio F, Ceci C, Grazia M, et al. Prevalence and geographical distribution of canine hemotropic mycoplasma infections in Mediterranean countries and analysis of risk factors for infection. Vet Microbiol. 2010;142:276-84

\section{Submit your next manuscript to BioMed Central and we will help you at every step:}

- We accept pre-submission inquiries

- Our selector tool helps you to find the most relevant journal

- We provide round the clock customer support

- Convenient online submission

- Thorough peer review

- Inclusion in PubMed and all major indexing services

- Maximum visibility for your research

Submit your manuscript at www.biomedcentral.com/submit 